\title{
Buka Tutup Jilbab di Kalangan Siswi SMA
}

\author{
Lili Afnita Wulandari ${ }^{1}$, Erda Fitriani ${ }^{2}$, \\ ${ }^{1,2}$ Universitas Negeri Padang \\ Email: $\underline{\text { liliafnita02@gmail.com, erdafitriani@fis.unp.ac.id. }}$
}

\begin{abstract}
Abstrak
Artikel ini bertujuan untuk menjelaskan penyebab perilaku buka tutup jilbab di kalangan siswi SMA Negeri 1 Solok Selatan. Penelitian ini dilakukan dengan pendekatan kualitatif dengan jenis penelitian studi kasus. Teknik pemilihan informan purposive sampling (sampel bertujuan) dengan jumlah informan sebanyak 22 orang. Pengumpulan data dengan cara observasi non partisipasi, wawancara mendalam dan studi dokumen, dan teknik analisis data dari Miles dan Huberman. Data dianalisis menggunakan teori etnosains yang dikembangkan oleh Goodenough yang menyatakan bahwa perilaku masyarakat suatu kebudayaan tergantung dengan pengetahuan yang ia miliki. Asumsi teori bahwa setiap masyarakat mempunyai suatu sistem yang unik dalam mempersepsikan dan mengorganisasikan fenomena material seperti benda-benda, kejadian, perilaku serta emosi. Berdasarkan hasil penelitian diperoleh kesimpulan bahwa perilaku buka tutup jilbab di kalangan siswi itu disebabkan karena pengetahuan agama yang rendah, Kasak dan Lameh saat memakai jilbab, peraturan sekolah yang mewajibkan berjilbab dan pengaruh lingkungan yang tidak mendukung untuk dapat memakai jilbab secara konsisten.
\end{abstract}

Kata kunci: Buka tutup jilbab, Jilbab, Siswi

\section{Abstract}

This article aims to explain the causes of the opening of the hijab narrative among female students of SMA Negeri 1 Solok Selatan. This research was conducted with a qualitative approach with the type of case study research. The technique of selecting informants was purposive sampling (purposive sampling) with 22 informants. Collecting data by means of non-participation observation, in-depth interviews and document studies, and data analysis techniques from Miles and Huberman. The data were analyzed using the ethnoscience theory developed by Goodenough which states that the behavior of the people of a culture depends on the knowledge they have. The theoretical assumption is that every society has a unique system for perceiving and organizing material phenomena such as objects, events, behavior and emotions. Based on the results of the study, it was concluded that the open and closed behavior of the headscarf among female students was due to low religious knowledge, Kasakd Lameh when wearing the hijab, school regulations that obliged the veil and environmental influences that did not support being able to wear the hijab consistently.

Keywords: Open and close the headscraft, Headscraft, Female students

\begin{tabular}{|c|c|c|}
\hline Received: January 20, 2021 & Revised: January 28, 2021 & Published: January 29, 2021 \\
\hline
\end{tabular}

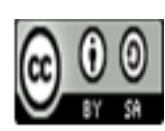




\section{Pendahuluan}

Dewasa ini penggunaan jilbab semakin berkembang, tahapan perkembangan jilbab memiliki fase sendiri yang diawali dengan munculnya gerakan Islam transnasional yang disertai dengan perkembangan tren yang ikut mempengaruhi penyebarluasaan jilbab melalui kapitalisme pasar (Ramadhini, 2017). Saat ini jilbab tidak lagi menjadi sesuatu yang asing di kalangan masyarakat mulai dari kalangan ibu-ibu, kaum muda, atau mahasiswa tak terkecuali juga siswi SMA.

Pada umumnya kaum muda lebih aktif mengikuti perkembangan model jilbab. Hal ini disebabkan kaum muda memiliki akses yang paling cepat terhadap teknologi informasi dan komunikasi, sehingga siswi secara langsung mudah tepengaruh untuk mengikuti dan meniru segala hal perubahan dalam dunia global, termasuk dalam hal pemilihan model jilbab (Choiratunnadzifah, 2013).

Pada dasarnya jilbab merupakan bagian penting untuk menutup aurat. Pemakaian jilbab diwajibkan bagi perempuan yang sudah baligh seperti tercantum dalam firman Allah QS: AlAhzab 59 bahwa perempuan wajib menutup auratnya yakni seluruh tubuh kecuali muka dan telapak tangan. Melalui ayat ini tekandung makna bahwa perempuan wajib memakai jilbab untuk menutup auratnya, menggunakan jilbab juga sebagai atribut untuk menunjukkan identitas diri sebagai perempuan muslim (Purwitasari, 2014). Dengan memakai jilbab sedikit banyaknya akan berpengaruh kepada jiwa perempuan sehingga dapat membentuk akhlak/budi pekerti yang luhur, hal ini dikarenakan berjilbab tidak hanya berkaitan dengan cara berjilbab, bentuk jilbab yang dipakai, ukuran atau pun nilai estetika semata, akan tetapi jilbab diharapkan mampu mencerminkan perilaku serta pribadi yang berakhlakul kharimah.

Perempuan yang awalnya belum mengenakan jilbab, berangsur-angsur memakai jilbab maka tanpa disadari akan mampu menuntun kepada hal yang positif dan menjadikan perempuan lebih tehormat (Noer, 2016). Namun pada kenyataannya masih sering kita jumpai perempuan tidak konsisten dalam memakai jilbabnya. Jilbab hanya di pakai pada saat-saat tertentu saja, seperti halnya pergi sekolah, di luar sekolah siswi ditemukan tidak mengenakan jilbab lagi. Tindakan membuka dan menutup jilbab ini dianggap sebagai hal biasa, namun jika dikaji secara mendalam, tentu saja bertentangan dengan syariat Islam karena dapat menggeser makna dan fungsi jilbab dan dianggap mempermainkan Agama (Riano, 2018).

Penelitan ini di fokuskan pada sekelompok siswi SMA Negeri 1 Solok Selatan yang mempraktekkan buka tutup jilbab, mereka memakai jilbab hanya pada saat tetentu saja, seperti saat pergi ke sekolah. Siswi dipilih sebagai objek penelitian karena pengetahuan mereka mengenai jilbab cukup banyak diajarkan di sekolah pada mata pelajaran Agama di jenjang kelas sebelumnya yakni SD/MI, SMP/MTs dan sekolah lainnya yang sederajat (Riano, 2018). Adapun alasan peneliti memiliki SMA Negeri 1 Solok Selatan sebagai lokasi penelitian ini adalah karena merupakan sekolah umum yang mewajibkan siswinya untuk memakai jilbab, diharapkan tidak hanya di lingkungan sekolah namun juga dipraktekkan dalam kehidupan sehari-hari.

Berdasarkan penelitian yang dilakukan oleh Anik Choiratunnadzifah (Universitas Islam Negeri Yogyakarta 2013) mengenai Jilbab dan Ketaatan Beragama Bagi Mahasiswi Muslim Fakultas Seni Pertunjukkan ISI Yogyakarta. Adapun hasil penelitiannya: a) Semata-mata karena Allah dan kesadaran diri dan memenuhi kewajiban sebagai seorang Muslimah yang taat, $b$ ) Wanita Muslimah yang konsisten berjilbab di Fakultas Pertunjukkan akan rela kehilangan kesempatan pementasan seni yang diinginkan sekalipun jika harus melepas jilbabnya (Choiratunnadzifah, 2013).

Sedangkan penelitian yang dilakukan oleh Anisa Aprilany (Universitas Negeri Semarang 2016) tentang Fenomena Jilbab Setengah Hari Di Kalangan Mahasiswa (Studi Kasus Mahasiswi di Kota Semarang), menunjukkan bahwa: 1) Pemaknaan jilbab bagi mahasiswi mendapat tanggapan berdasarkan sudut pandang yang berbeda-beda yakni makna jilbab bagi pengguna jilbab konsisten dan makna jilbab bagi pengguna jilbab setengah hari. 2) Proses sosialisasi penggunaan jilbab dipengaruhi sosialisasi primer dan sosialisasi sekunder. 3) faktor adanya anggapan berjilbab

Culture \& Society: Journal of Anthropological Research Vol. 2, No. 3, Th. 2021 
dinilai lebih cantik, trendy, 4) Persepsi mahasiswa yang pro dan kontra tehadap penggunaan jilbab (Aprilany, 2016).

Fenomena terkait pemakaian jilbab selalu berkembang dan menyesuaikan dengan perkembangan zaman. Penelitian terkait jilbab juga telah banyak dilakukan, biasanya kepada tren model, namun yang menjadi aspek kebaruan dan membedakan penelitian ini dengan penelitian yang sudah ada yakni mengkaji faktor penyebab perilaku tidak konsisten dalam memakai jilbab. Penelitan ini bertujuan untuk memperdalam penelitian terdahulu dengan sudut pandang Sosiologi dan juga Antropologi Agama.

Penelitian ini dianalisis dengan teori etnosains yang dikembangkan oleh Goodenough yang menyatakan perilaku masyarakat suatu kebudayaan dipengaruhi oleh pengetahuan yang ia miliki. Budaya menurut Goodenough terdiri dari segala sesuatu yang harus diketahui atau dipercayai seseorang agar ia dapat berperilaku sesuai dengan cara yang dapat diterima dalam masyarkat. karena pengetahuan masyarkat sangat luas cakupannya, maka seorang antropolog tidak meneliti semua pengetahuan yang ada, melainkan hanya mengenai hal-hal tertentu saja yang ia minati.

\section{Metode Penelitian}

Penelitian ini menggunakan pendekatan kualitatif. Pendekatan ini menekankan pada proses, makna, pemahaman dan perilaku yang didapat melalui kata-kata (Creswell, 2016). Pendekatan kualitatif dipilih karena metoda ini dianggap mampu menemukan penyebab buka tutup jilbab di kalangan siswi SMA Negeri 1 Solok Selatan. Jenis penelitian yang digunakan adalah studi kasus yaitu penelitian yang memberikan arti lebih mendalam pada peristiwa atau fenomena yang terjadi dengan cara yang tersistematis dalam melakukan pengamatan, pengumpulan data, analisis informasi, dan pelaporan hasil (Afrizal, 2016). Berdasarkan proses penelitian tersebut sehingga diketahui penyebab perilaku buka tutup jilbab di kalangan siswi SMA Negeri 1 Solok Selatan.

Penelitian ini dilakukan di SMA Negeri 1 Solok Selatan. Lokasi penelitian ini di pilih karena sekolah ini merupakan sekolah umum yang mewajibkan siswinya untuk menggunakan jilbab. tidak hanya di lingkungan sekolah, diharapkan dapat dipraktekkan di luar sekolah. Teknik pemilihan informan dengan cara purposive sampling (sampel bertujuan). Informan dalam penelitian ini berjumlah 22 orang diantaranya: 16 orang siswi, 2 orang siswa, 2 orang guru, 2 orang wali murid/orang tua siswi.

Metode pengumpulan data yang digunakan adalah observasi, wawancara mendalam, dan studi dokumen. Untuk mendapatkan keabsahan dan kebenaran data yang telah dikumpulkan maka peneliti perlu melakukan triangulasi data. Dalam penelitian ini menggunakan triangulasi sumber dan metode. Analisis data yang dilakukan yakni menggunakan model analisis interakif dari Miles dan Huberman dengan tahapan pengumpulan data, reduksi data, penyajian data, dan penarikan kesimpulan.

\section{Hasil dan Pembahasan}

\section{Konsep Buka tutup jilbab di Kalangan Siswi SMA Negeri 1 Solok Selatan}

Konsep buka tutup jilbab merupakan sebuah konsep emik yang peneliti temukan dalam penelitian ini. Konsep emik merupakan deskripsi dari analisis yang dilakukan dalam konteks skema dan kategori konseptual yang dianggap bermakna oleh partisipan dalam suatu peristiwa konsep yang digunakan harus memenuhi gagasan ketepatan, reabillitas dan akurasi, deskripsi emik harus divalidasi oleh konsensus yakni konsensus para informan natives (Saifuddin, 2006).

Dari hasil temuan penelitian konsep buka tutup jilbab ditafsirkan sebagai perilaku tidak konsisten dalam memakai jilbab, fungsi jilbab yang dimaksud adalah untuk menutupi kepala hingga ke dada yang menjadi bagian dari aurat perempuan. Siswi memakai jilbab hanya pada saatsaat tertentu, tidak digunakan sepanjang hari, ini berdasarkan pengamatan yang peneliti lakukan

Culture \& Society: Journal of Anthropological Research Vol. 2, No. 3, Th. 2021 
siswi memakai jilbab saat ke sekolah, setelah pulang sekolah jika bepergian keluar rumah tidak memakai jilbab lagi. Sementara esensi pemakaian jilbab saat perempuan berada di luar rumah (ranah publik) karena khawatir dilihat auratnya oleh orang yang bukan mahram. Sekalipun di rumah tetapi ada non mahram juga wajib menutup aurat.

\section{Penyebab Buka Tutup Jilbab di Kalangan Siswi SMA Negeri 1 Solok Selatan}

Berdasarkan hasil penelitian dan observasi mengenai buka tutup jilbab di kalangan siswi SMA Negeri 1 Solok Selatan di dapatkan 4 poin penyebab paling mendasar yaitu:

Pertama, Pengetahuan Agama yang masih rendah. Siswi SMA Negeri 1 Solok Selatan yang tidak konsisten dalam memakai jilbab disebabkan karena kurang memahami ajaran Agama Islam. Pengetahuan berjilbab temasuk salah satu pengetahuan yang dimiliki oleh setiap perempuan Muslim dan temasuk kedalam jajaran pengetahuan yang dianggap penting sebagai perwujudan bentuk taat kepada Allah SWT. (Noer, 2016). Pengetahuan Agama dalam hal pemakaian jilbab dapat diperoleh melalui pengalaman kehidupan sehari-sehari, dengan mencari dan membaca berbagai literatur kegamaan Islam atau pun dalil-dalil terkait pemakaian jilbab.

Siswi SMA Negeri 1 Solok Selatan yang tidak konsisten memakai jilbab dikarenakan tidak mengetahui makna dan fungsi jilbab yang sesungguhnya. Pengetahuan yang mereka miliki sebatas pengetahuan umum saja, yaitu jilbab sebagai alat penutup kepala. Sebagaimana yang disampaikan oleh informan SO (18 tahun) ia menyatakan bahwa:

"...sepengetahuan wak kak, pakai jilbab tu wajib, untuk nutuik aurat, Cuma alasannyo apo kurang tau wak kak, wak se masih acok "buka tutuik jilbab". wak ndak skolah di MTsN do, tu ndak ado balajar itu do. Sadangkan nan sakolah di MTs bahkan ado juo nan indak bajilbab. Tagantuang urang lo kak, caliak-caliak lo lu anak sia nyo. Skolah dimanyo. Kok pesantren tu wajarnyo.kok nyo "bukak tu tutuik" lo kapalo liak tu lain kecek urang lai..."

Bahasa Indonesia:

"...sepengetahuan saya kak, pakai jilbab itu wajib, untuk menutup aurat, Cuma alasannya apa saya kurang tahu kak, saya sendiri masih buka tutup jilbab. saya tidak sekolah di MTsN kak, jadi tidak ada belajar tentang jilbab itu kak. Sedangkan yang sekolah di MTsN saja ada yang tidak memakai jilbab, itu tergantung orangnya kak, lihat dulu anak siapa dia. Sekolah dimana. Kalau di pesantren tentu wajar saja. Kalau dia buka tutup nanti lain penilaian masyarakat.

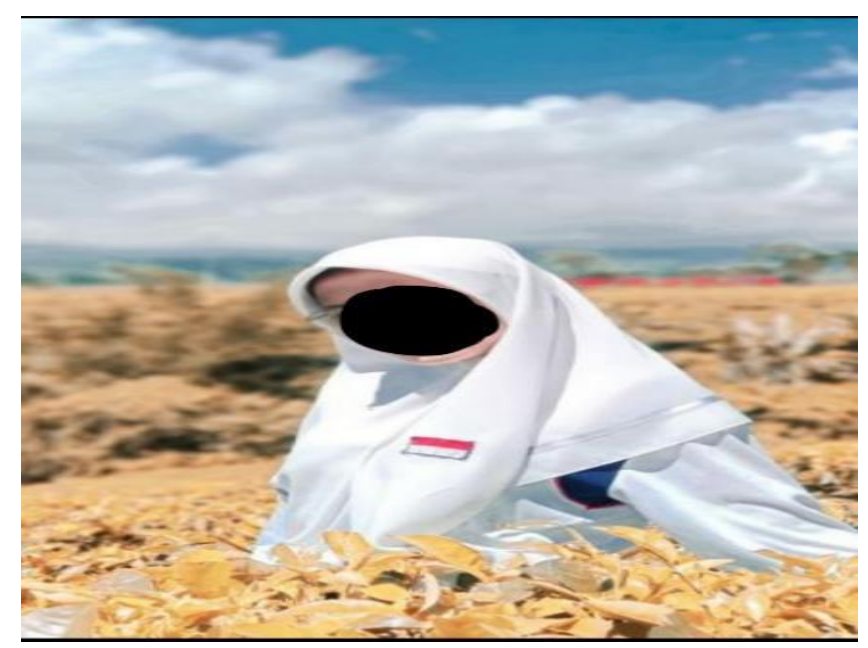

Gambar 1. SO memakai jilbab 


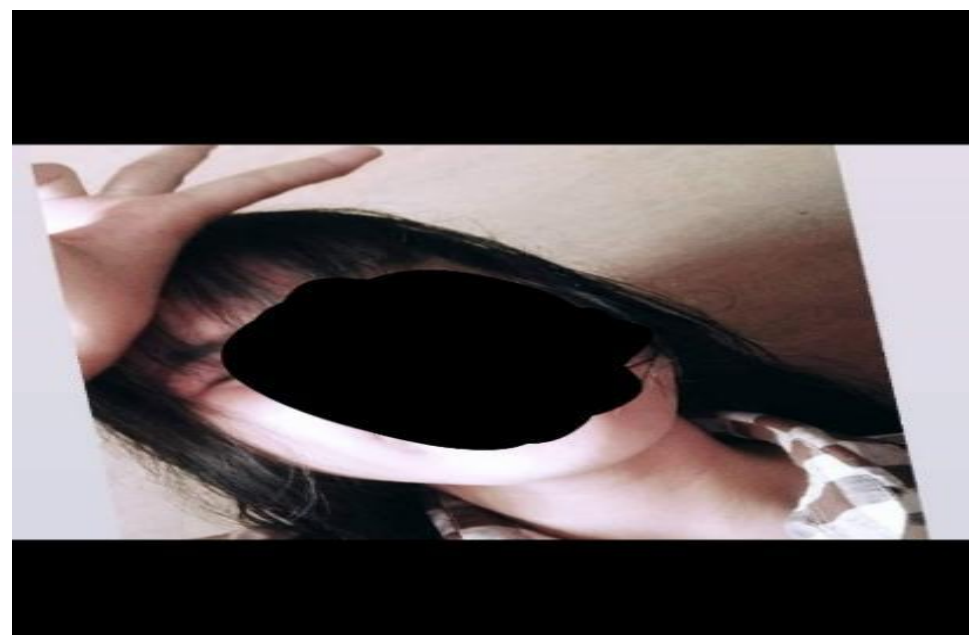

Gambar 2. SO tidak memakai jilbab

Dari apa yang disampaikan oleh SO ia masih sering buka tutup jilbab disebabkan ketidaktahuan dia tentang alasan diwajibkannya memakai jilbab, ia tidak mengetahui ayat-ayat Al-Quran yang memerintahkan untuk memakai jilbab. SO mengaku belum pernah menelusuri ayat-ayat yang berhubungan dengan pemakaian jilbab. Sangat dimungkinkan banyak perempuan muslim yang belum mengetahui dalil-dalil Al-Quran tekait penggunaan jilbab sehingga mereka masih buka tutup jilbab (Yulikhah, 2016).

Urgensi memakai jilbab untuk menutup aurat adalah ketika berada di luar rumah (memasuki ranah publik). Esensinya adalah untuk menghindari hal-hal yang tidak diinginkan seperti terjadinya pelecehan terhadap perempuan, yang mengarah pada seksualitas sebab perempuan merupakan makhluk yang memiliki potensi seks yang lebih besar daripada laki-laki, oleh karenanya penting bagi perempuan untuk menutup auratnya demi menjaga kehormatannya. Selain itu juga membantu lelaki untuk menundukkan pandangannya (Jasmani, 2013).

Hal ini dianalisis menggunakan teori etnosains yang dikembangkan oleh James Spradley tentang Sistem of Knowledge and Cognition Given Culture Tipical of Culture, yaitu pengetahuan yang dimiliki oleh suatu masyarakat itu berbeda dengan masyarakat lainnya. Dalam penelitian ini pengetahuan informan tentang jilbab masih rendah itulah yang menyebabkan informan masih buka tutup jilbab, berbeda dengan siswi yang konsisten mereka sudah mengetahui tentang urgensi diwajibkannya berjilbab yaitu: untuk melindungi perempuan dari tindak kriminal yang menjadikan perempuan sebagai korban pelecehan seksual, untuk kesehatan kulit, dan juga menjadikan perempuan lebih tehormat (Wijayanti, 2017).

Kedua, Kasak dan Lameh saat memakai jilbab. Siswi SMA Negeri 1 Solok Selatan mengetahui bahwa perempuan yang sudah baligh diwajibkan untuk menutup aurat, guna terhindar dari hal-hal yang tidak dinginkan, seperti pelecehan tehadap kaum perempuan, berjilbab juga dapat sebagai kontrol perilaku dan mencerminkan budi pekerti yang luhur. Disamping siswi sudah mengetahui kewajiban memakai jilbab namun menjalankannya terasa berat, dengan alasan seperti, kasak (gerah, panas), dan lameh (tidak nyaman). Seperti penuturan informan DA (19 tahun):

“...Jilbab tu untuk manutuik aurat, manjago diri dari pandangan kalaki. Cuman kalau ndak talalu tabukak kan ndak baa do kak, asakan baju lai sopan. apolai hari angek lo. Kasak...lameh bajilbab tu. wak ndak paham bana lo do kak, iman wak masih lamah. Kalah wak jo ukhty nan bajilbab dalam tu. wak se masih acok ndk bajilbab kalua-kalua..."

Bahasa Indonesia:

"...jilbab itu untuk menutup aurat, menjaga diri dari pandangan lelaki. Jika tidak telalu terbuka, 'kan tidak apa-apa kak, asalkan bajunya sopan. Apalagi cuaca panas. Gerah...tidak nyaman. Saya

Culture \& Society: Journal of Anthropological Research Vol. 2, No. 3, Th. 2021 
tidak terlalu paham kak, iman saya masih lemah. Kalah dengan ukhty yang pakai jilbab dalam. Saya aja masih sering tidak pakai jilbab keluar-keluar".

Dari apa yang disampaikan oleh informan dapat disimpulkan bahwa siswi yang masih buka tutup jilbab disebabkan karena rasa tidak nyaman, gerah, konsep emik kasak dan lameh. Hal ini dianalisis dengan bidang kajian etnosains yang memusatkan perhatian kepada kebudayaan yang bertujuan untuk mengetahui gejala-gejala yang dianggap penting oleh masyarakat dan bagaimana mengorganisirnya sebagai gejala dalam pengetahuannya. Dalam hal ini siswi memiliki pengetahuan tentang jilbab, bahwasanya berjilbab itu wajib untuk menutup aurat bagi perempuan muslim yang sudah baligh. Akan tetapi pengetahuan yang dimiliki oleh siswi telah terorganisir sebatas pengetahuan saja, tidak untuk diimplementasikan dalam kehidupan sehari-hari. Sehingga siswi masih buka tutup jilbab, dengan alasan-alasan yang konsep emik kasak dan lameh sebenarnya bertentangan ajaran Islam.

Ketiga, peraturan sekolah yang mewajibkan berjilbab. Sekolah merupakan lembaga pendidikan yang memiliki pengaruh cukup besar dalam pembentukan sikap dan perilaku seorang anak, di sekolah anak belajar mempersiapkan diri untuk penguasaan peran-peran baru di kemudian hari dikala sang anak telah menginjak usia dewasa (Nurfiqin, 2013). Sekolah sebagai lembaga pendidikan juga berperan sebagai agen sosialisasi serta untuk penanaman nilai-nilai pendidikan dan keagamaan.

Adapun berdasarkan hasil penelitian siswi memakai jilbab dikarenakan ada aturan sekolah yang mewajibkan berjilbab. Ini terdapat dalam Tata Tertib Sekolah Pasal 3 yang mengatur tentang cara berpakaian siswi, apabila dilanggar akan mendapatkan sanksi berupa teguran atau peringatan dari pihak berwenang. Adapun saat berada di luar lingkungan sekolah siswi ditemukan tidak memakai jibab lagi. Secara tidak langsung siswi memakai jilbab karena mengikuti peraturan sekolah saja bukan karena kesadaran akan kewajibannya sebagai Muslimah. Berdasarkan aancara dengan informan TF (17 tahun):

"...Saya belum bisa konsisten pakai jilbab, nggak terbiasa, itulah kenapa saya masih suka bukak tuup jilbab. kadang kesekolah aja pake jilbab. sebab sekolah mewajibkan untuk memakai jilbab. canggung juga tidak pakai jilbab kesekolah sebab semua teman perempuan pake jilbab. lagian kalo kesekolah udah biasa sih, cuman kalo pergi deket-deket rumah agak males aja..."

Dari informasi yang disampaikan oleh informan TF, ia menyatakan bahwa memakai jilbab hanya saat pergi ke sekolah saja, sebab memang ada aturan yang mewajibkan siswi untuk memakai jilbab, jika dilanggar maka akan ada sanksi. Buka tutup jilbab karena adanya peraturan sekolah yang bersifat memaksa sehingga mau tidak mau siswi harus mematuhi (Yulikhah, 2016). $\mathrm{Hal}$ ini dapat dianalisis dengan teori etnosains yang menekankan pada pengungkapan kebudayaan yang ada di dalam masyarakat itu berupa nilai dan norma yang dilarang maupun dibolehkan. SMA Negeri 1 Solok Selatan mempunyai tata tertib untuk memakai jilbab di sekolah, jika dilanggar maka akan ada sanksi. Pemakaian jilbab, diharapkan bukan hanya di lingkungan sekolah namun juga saat berada di luar lingkungan sekolah. Sekolah juga telah mengupayakan untuk membangun kesadaran siswi memakai jilbab, yakni dengan memberikan nasehat tentang pentingnya menutup aurat, melalui pelajaran Agama dan terintegrasi dalam mata pelajaran lainnya. Selain itu guru juga memberikan teguran, dan ajakan untuk menuntun siswi menjadi muslimah sejati dengan menutup aurat.

Keempat, lingkungan yang tidak mendukung. Lingkungan sangat berpengaruh besar dalam proses belajar dan menerapkan hasil pembelajaran yang telah diperoleh. Siswi masih buka tutup jilbab disebabkan oleh pengaruh lingkungan keluarga, lingkungan pertemanan dan lingkungan masyarakat yang tidak mendukung untuk dapat memakai jilbab secara konsisten.

\section{Lingkungan keluarga}

Lingkungan keluarga memiliki pengaruh yang sangat besar dalam proses belajar dan penanaman nilai-nilai agama, budaya dan juga pendidikan. Sebab keluarga merupakan wadah utama untuk memberikan pendidikan. Orang tua sangat berpengaruh dalam penanaman nilai-

Culture \& Society: Journal of Anthropological Research Vol. 2, No. 3, Th. 2021 
nilai yang dianutnya (Utari, 2019). Seorang anak mempratekkan dan akan terbiasa memakai jilbab jika orang tua menyuruhnya anak untuk berjilbab saat usia dini, untuk dapat menjadi teladan bagi anak orang tua terlebih dahulu harus memberikan contoh. Berdasarkan wawancara dengan informan MSA (17 tahun):

"...Mama tidak pakai jilbab kak, sesekali ada jika pergi ke pasar, kalau seandainya mama menyuruh sejak masih kecil, mungkin sekarang juga bisa terbiasa seperti teman-teman yang lain..."

Berdasarkan informasi yang disampaikan oleh informan bahwa ia masih buka tutup jilbab itu karena orang tuanya tidak mengharuskannya memakai jilbab. Idealnya orang tua memberikan teladan bagi anaknya untuk dapat memakai jilbab secara konsisten, namun kenyataan yang ditemukan orang tua sendiri tidak memberikan teladan, masih buka tutup jilbab.

\section{Lingkungan pertemanan}

Lingkungan pertemanan sangat berpengaruh dalam proses belajar seorang individu, sebab mampu membentuk prinsip dan pemahaman yang tidak dapat dikontrol oleh orang tua (Widahyanti, 2016), siswi buka tutup jilbab dipengaruhi lingkungan pertemanan sesuai dengan informasi yang disampaikan oleh informan MIA (17 tahun):

"...Saya pakai belum terbiasa berjilbab sepanjang hari, jarang, ngumpul sama teman sesekali ada, tapi sering tidak. Kalau pergi dengan teman-teman nanti saya pakai jilbab, mereka tidak, itu kan tidak seru. Terlihat tidak kompak, kecuali ketika menghadiri undangan pernikahan itu kami kompak berjilbab. Kadang bikin janji pakai warna sama, supaya telihat serasi..."

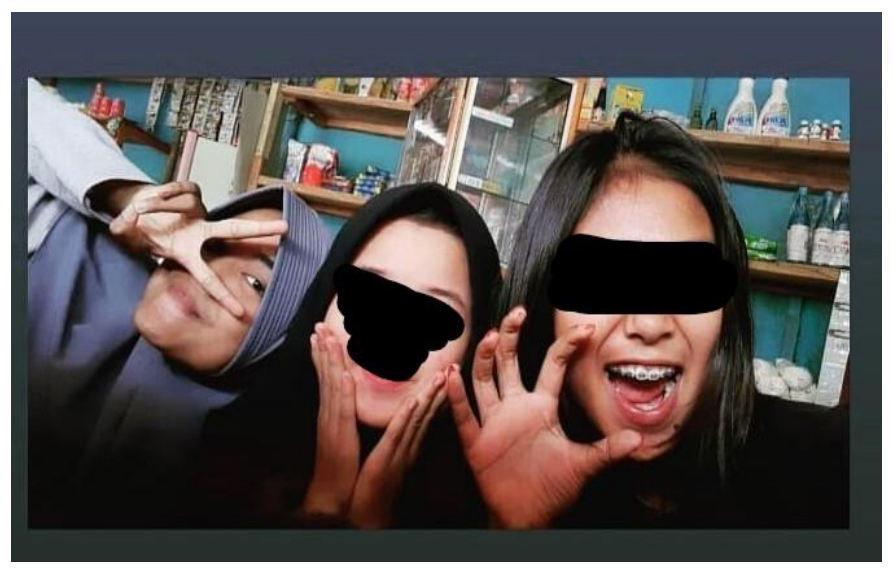

Gambar. Informan MIA memakai jilbab saat berkumpul bersama teman

Sumber: dokumentasi penulis 20 Desember 2020

Berdasarkan yang disampaikan informan ia memakai jilbab saat berkumpul bersama temantemannya, ia mendapat ejekan bahkan hasutan untuk tidak memakai jilbab, karena merasa canggung berbeda dari teman yang lain tekadang MIA masih buka tutup jilbab dengan alasan solidaritas supaya terlihat kompak.

\section{Lingkungan Masyarakat}

Lingkungan masyarakat juga ikut mempengaruhi keteguhan hati siswi untuk dapat konsisten berjilbab. Ketika seorang siswi yang biasanya tidak memakai jilbab di sekitar rumah, tiba-tiba mengenakan jilbab maka itu menjadi hal yang aneh dalam pandangan masyarakat, telebih hubungan kekerabatan yang masih sangat erat, masyarakat sekitar atau tetangga memiliki kepedulian yang tinggi alih-alih memberikan pujian malah terkesan mengejek dan mengandung unsur cibiran. Persepsi masyarakat yang menganggap bahwa jilbab biasanya dipakai oleh orang tua-tua saja. Hal ini yang menyebabkan siswi tidak percaya diri yang berakibat buka tutup jilbab karena harus menyesuaikan waktu dan tempat yang cocok untuk memakai jilbab. 
Lingkungan yang tidak mendukung dapat dianalisis dengan teori etnosasins yang memusatkan kebudayaan sebagai prinsip untuk menciptakan, membangun peristiwa, mengumpulkan individu, atau orang banyak. Siswi buka tutup jilbab itu disebabkan karena lingkungan yang tidak mendukung untuk dapat konsisten berjilbab, baik itu lingkungan keluarga, lingkungan pertemanan, serta lingkungan masyarakat yang seharusnya dapat memberikan motivasi untuk berjilbab secara konsisten, namun kenyataan lingkungan tidak menciptakan kondisi ideal yang dapat mendukung siswi untuk dapat konsisten dalam memakai jilbab. Persepsi lingkungan masyarakat bahwa jilbab biasanya hanya dipakai oleh ibu-ibu atau orang tua-tua saja. Jika siswi SMA yang biasanya tidak memakai jilbab di sekitar rumah, tiba-tiba memakai jilbab terlihat sedikit aneh, dan menarik jadi bahan bully-an bagi ibu-ibu yang tinggal di sekitar rumahnya sehingga siswi belum bisa konsisten memakai jilbab.

\section{Kesimpulan}

Berdasarkan hasil penelitian dapat disimpulkan penyebab tejadinya buka tutup jilbab di kalangan siswi SMA Negeri 1 Solok Selatan diantaranya adalah 1) Pengetahuan Agama yang rendah, sehingga siswi tidak mengetahui makna dan fungsi jilbab yang sesungguhnya dan menyebabkan siswi tidak konsisten berjilbab. 2) Kasak dan Lameh saat memakai jilbab, maksudnya yaitu siswi mengetahui bahwa perempuan islam yang sudah baligh diwajibkan memakai jilbab untuk menutup aurat, tetapi karena alasan gerah, ribet, tidak nyaman dan tidak terbiasa, siswi melakukan buka tutup jilbab. 3) Peraturan sekolah yang mewajibkan untuk memakai jilbab, siswi memakai jilbab karena mengikuti peraturan sekolah, di luar lingkungan sekolah siswi tidak memakai jilbab karena siswi tidak terikat dengan tata tertib sekolah. 4) Lingkungan yang tidak mendukung, siswi masih buka tutup jilbab disebabkan karena faktor lingkungan keluarga dan lingkungan pertemanan dan lingkungan masyarakat yang membuat siswi tidak bisa konsisten berjilbab seperti mendapat ejekan, cibiran dan cemoohan sehingga menjadikan siswi merasa minder dan tidak percaya diri yang berakibat pada perilaku buka tutup jilbab karena harus menyesuaikan situasi dan kondisi, kapan, dimana dan bersama siapa harus menggunakan jilbab. Diantara 4 poin penyebab buka tutup jilbab di kalangan siswi SMA N 1 Solok Selatan, yang menjadi point pentingnya adalah disebabkan rendahnya pengetahuan siswi tentang pengetahuan agama dalam hal pemakaian jilbab. Berdasarkan teori etnosains yang dikembangkan oleh Goodenough bahwa perilaku individu itu dipengaruhi oleh pengetahuan yang ia mililiki. Pengetahuan berjilbab dapat diperoleh melalui pengalaman di lingkungan kehidupan sehari-hari seperti lingkungan keluarga, lingkungan pertemanan dan lingkungan masyarakat.

\section{Daftar Pustaka}

Afrizal, A. (2016). Metode Penelitian Kualitatif. Jakarta: PT Raja Grafindo Persada.

Aprilany, A. (2016). Fenomena "Jilbab Setengah Hari" di Kalangan Mahasiswa (Studi Kasus Pada Mahasiswi di Kota Semarang. Disertasi. Universitas Negeri Semarang.

Choiratunnadzifah, A. (2013). Jilbab dan Ketaatan Beragama Bagi Mahasiswi Muslim Fakultas Seni Pertunjukkan ISI Yogyakarta. Skripsi. UIN Sunan Kalijaga Yogyakarta.

Creswell, J. W. (2016). Pendekatan Metode Kualitatif, Kuantitatif, dan Campuran. Yogyakarta: Klik Press.

Jasmani. (2013). Hijab dan Jilbab Menurut Hukum Fiqih. Jurnal Al-'Adl, 6(2), 62-75.

Noer, A. dkk. (2016). Pengaruh Pengetahuan Berjilbab dan Perilaku Keagamaan Terhadap Motivasi Berjilbab Mahasiswi Pendidikan Agama Islam (PAI) Universitas Islam Riau (UIR). Jurnal Pendidikan Agama Islam Al-Thariqah, 1(2), 172-192.

Nurfiqin, M. . (2013). Pemakaian Jilbab Di Kalangan Siswi SMA (Studi Tentang Sosialisasi Pemakaian Jilbab Pada Siswi SMA Negeri 2 Grabag Magelang. Disertasi. Universitas Negeri Semarang.

Culture \& Society: Journal of Anthropological Research Vol. 2, No. 3, Th. 2021 
Purwitasari, I. (2014). Motivasi Siswa Memakai Jilbab Di Sekolah Menengah Atas Negeri 2 Purwokerto Kabupaten Banyumas. Disertasi. IAIN Purwokerto.

Ramadhini, E. (2017). Jilbab Sebagai Reperentasi Simbolik Mahasiswi Muslim di Universitas Indonesia. Masyarakat: Jurnal Sosiologi, 22(1), 81-103.

Riano, D. T. (2018). Buka Tutup Jilbab di Kalangan Remaja Studi Tentang Tindakan Sosial Pada Siswi SMA dan SMK. Disertasi. Universitas Airlangga.

Saifuddin, A. F. (2006). Antropologi Kontemporer Suatu Pengantar Kritis Mengenai Paradigma. Jakarta: Kencana Predanamedia Group.

Utari, A. A. D. (2019). Fenomena Jilbab Syar'i di Kalangan Mahasiswa Fakultas Ilmu Sosial Universitas Negeri Makassar. Jurnal Sosialisasi: Jurnal Hasil Pemikiran, Penelitian dan Pengembangan Keilmuan Sosiologi Pendidikan, 1(1), 7-12.

Widahyanti, E. (2016). Faktor-Faktor yang Menyebabkan Kurangnya Minat Menggunakan Jilbab Pada Remaja Desa Margoyoso Sumberejo Tanggamus. Disertasi. IAIN Raden Intan Lampung.

Wijayanti, R. (2017). Jilbab Sebagai Etika Busana Muslimah Dalam Perspektif Al-Qur'an. Cakrawala: Jurnal Studi Islam, 12(2), 151-170.

Yulikhah, S. (2016). Jilbab Antara Kesalehan dan Fenomena Sosial. Jurnal Ilmu Dakwah, 36(1), 96117. https://doi.org/http://dx.doi.org/10.21580/jid.361.1627 